NBER WORKING PAPER SERIES

PREDICTING EXCHANGE RATE CRISES: MEXICO REVISITED

Linda S. Goldberg.

Working Paper No. 3320

NATIONAL BUREAU OF ECONOMIC RESEARCH

1050 Massachusetts Avenue

Cambridge, MA 02138

Apri1 1990

This paper is part of NBER's research program in International Studies. Any opinions expressed are those of the author and not those of the National Bureau of Economic Research. 
NBER Working Paper $\# 3320$

Apri1 1990

\title{
PREDICTING EXCHANGE RATE CRISES: MEXICO REVISITED
}

\begin{abstract}
This paper predicts ex-ante the probability of currency crises and size of expected devaluations month by month for Mexico between 1980 and 1986 using a heterodox linear discrete time model of exchange rate crises. The forces contributing to speculative attacks on the Mexican peso include internal money creation, external credit shocks, and relative price shocks. The framework proves highly successful for generating forecasts of the probability of speculative attacks on the peso and for predicting lower bounds for postcollapse exchange rates using a range of assumptions about critical levels of central bank reserve floors. Simulation results suggest that reducing domestic credit growth, increasing the uncertainty surrounding this growth, and reducing the size and perhaps increasing the frequency of currency realignments might have greatly reduced the amount of currency speculation against the peso in some of the crisis periods between 1980 and 1986 .
\end{abstract}

\author{
Linda S. Goldberg \\ New York University and NBER \\ Department of Economics \\ 269 Mercer Street \\ New York, NY 10003
}




\section{Introduction $^{1}$}

The theory of exchange rate crises has received considerable attention in recent years ${ }^{2}$ because of both the legacy of the debt crisis of the early 1980s and the sharp exchange rate realignments of the mid 1980s. Though there has been no shortage of actual crises, very few attempts have been made at applying and testing crisis models. In this paper a discrete time model of a collapsing exchange regime is applied to the experiences of Mexico, 1980 to 1986 . The model is used to assess the probability that the existing controlled exchange rate will be collapsed by a speculative attack on central bank foreign exchange reserves. It also is used to generate forecasts of lower bounds for sustainable post-collapse exchange rates.

An exchange rate crisis can take the form of either a discrete devaluation of a controlled exchange rate or a switch to a floating rate accompanied by a sharp speculative attack on central bank holding of foreign exchange reserves. The dynamics of the collapse as rooted in domestic money market equilibrium: when there is excess domestic credit creation, money market equilibrium can be achieved through offsetting reductions in central bank foreign exchange reserves or by exchange rate adjustment [Flood and Garber (1984)]: Under a fixed (or controlled) rate regime, as long as foreign exchange reserves remain in positive supply, monetary authorities can succeed at sustaining the exchange rate through the purchase of domestic currency and sale of foreign exchange reserves. If speculators perceive that an attack on central bank reserves can force the exchange rate to be devalued and the exchange regime abandonned, they

\footnotetext{
${ }^{1}$ An earlier version of this paper benefited from the helpful comments of Peter Kenen, Bill Branson, and seminar participants at New York University and Columbia University. The C.V. Starr Center of NYU is gratefully acknowledged for its support. George Kyriacou and Shirley Wang provided valuable research assistance.

${ }^{2}$ For example, see Krugman (1979), Flood and Garber (1984), Obstfeld (1984), Flood and Hodrick (1985); Buiter (1987), Grilli (1986), and Goldberg (1988).
} 
will deplete reserves by their attack, eliminate the central bank's ability to defend the overyalued currency and force the realigment. Models of collapse endogenousiy predict the timing and probability of speculative attacks and forecast lower bounds for the post-collapse exchenge rates.

The potential of this line of research hat already been demonstrated. For example, van Winbergen (1987) shows that the sustainability of the move from a flexible to a fixed exchange rate as undertaken in Brazil, Israel and Argentina with the intent of controlling ranaway inflation can be severely limited by the pursuit of inconsistent monebary and fiscal policies. Blanco and Garber's (1986) application of a collapse model to he Mexican experience [1973 to 1982] Hilustrated the predictive potential of these models concluding that "devaluabions, both in and out of sample, did occur when the conditional exchange rate set by the central bank's policy rule exceeded the fixed excharge rate.. Furthermore, the expected exchange rates conditional on devaluation are close to the values that actually materialized in the major episodes." Cumby and var Wijnbergen's (1988) application of a similar model to the crawling peg experience of Argentina $[1979$ and 1981] led them to conclude that the domestic credit growth strategy pursued by the Argentine governent nearly completely undermined the announced crawling exchange rates.

While these studies provide evidence for the qualitative and intuitive success of applying these linear discrete time models, the results can be improved upon and broadened in a number of dimensions. Restrictive assumptions prevailing in previous studies include strict purchasing-power-parity (PPP), interest rate parity, and the unresponsiveness of the demand for real balances to currency substitution motives. In addition, a richer specification of the forces contributing to crises can be modelled. While domestic credit shocks are still expected to be the dominant force in triggering 
speculative attacks on a currency, the Goldberg modification of Flood and Garber is applied in this paper to also track the significance of external credit shocks and relative price shocks. It is shown that the relative price shocks played an important in role in the dynamics of the peso crises. This is not the case for external credit shocks in the 1980s.

The remainder of the paper is organized as follows. Section I describes the extended collapse model. Section II provides a summary of the currency history for Mexico in the 1980s. Section III presents the procedures used for data analysis and describes the iterative estimation procedure used for generating month-by-month predictions of post-collapse exchange rates and collapse probabilities for Mexico. Section IV provides out-of-sample estimates of precicted shadow exchange rates and collapse probabilities under a range of assumptions, including structural breaks in money demand behavior. Out-of-sample forecasts are compared with those generated by Blanco and Garber for a subperiod of our study. Section $V$ analyzes the forces contributing to Mexico's crises and provides simulations of crises under different patterns of shocks to the Mexican economy. Section VI concludes.

\section{The Extended Collapse Model}

The discrete-time model relies on a money market equilibrium condition which determines either the equilibrium exchange rate under a flexible exchange system or the endogenous path of central bank reserves under a controlled rate system. ${ }^{3}$ The demand for real money balances is elastic with respect to nominal interest rates $\left[i_{t}\right]$, domestic real income $\left[\mathrm{y}_{t}\right]$, and the desire to substitute domestic currency for foreign currency when there is some expectation of a change in the nominal exchange rate, $S_{t}$.

\footnotetext{
${ }^{3}$ The model presented in this section is an extended version of Flood and Garber (1984).

Results are discussed in depth in Goldberg (1988).
} 


$$
\mathbb{M}^{\mathrm{i}} / Q_{t}=a_{0}-a_{1} i_{t}+a_{2} y_{t}-a_{3} E_{t}\left[S_{t+1} \xi_{t}-S_{t}\right] / S_{t}
$$

Rational forecasts of exchange rate changes are calculated usirg avallable current and past information summarized by $\xi_{t}$. Qt the price deflator on nominal money balances; contains both traded and nontraded gcods prices, $P_{t}$ and $P_{t}{ }^{*} S_{t}$, weighted by $\alpha_{t}$, the share of donestic goods in expenditure.

$$
Q_{t}=\alpha_{t} P_{t}+\left(1-\alpha_{t}\right) S_{t} P^{*}
$$

Domestic and toreign goods prices diverge due to $\rho_{t}$, medium term systematic PPP wiolations, ${ }^{4}$ and $a_{t}$, short term shocks to relative prices.

$$
P_{t} / S_{t}=P_{t}^{*}+\rho_{t}+n_{t}
$$

Generalized efficiency between donestic and foreign asset is reflected in the return spread and the risk premim on domestic assets.

$$
i_{t}=i_{t}^{*}+s_{t}\left[S_{t+1} * \xi_{t}-s_{t}\right] / s_{t}+r_{t}
$$

The supply of money $M^{3}$ ] has two components, the stock of central bank foreigr exchange reserves $\left[\mathrm{R}_{\mathrm{t}}\right]$ and the stock of domestic credit $\left[D_{\mathrm{t}}\right]$.

$$
M_{t}^{s}=E_{t}+D_{t}
$$

Domestic credit creation (and domestic spending excesses) are viewed as the primary reason for seserve depletion and an eventual exchange regime collapse. Thus, the domestic credit component of the money supply is modelled as evolving according to a trend rate that reflects the mean basic deficit $\left\{\mu_{\mathrm{t}}\right\}$.

$$
D_{t}=D_{t-1}+\mu_{t}+\epsilon_{t}
$$

The shocks to domestic credit creation are generally treated as random disturbances analytically similar to a first order process driving domestic credit creation [Blanco and Garber (1986)]. Cumby and yan Wijnbergen (1988) interpret domestic credit expansion as

\footnotetext{
${ }^{4} T h i s$ wedge also could be sensitive to expected exchange rate changes (Connolly and Taylor (1984) and Flood and Hodrick (1985)].
} 
mirroring trend fiscal deficits, $\mu_{t}$, subject to random disturbances $\epsilon_{t}$. However, these disturbances may be decomposed by source: i) random revenue or expenditure affecting the need to monetize government deficits $\left[\gamma_{t}\right]_{;}$and ii) randorn and constrained access to external credit that makes uncertain the share of government deficits to be financed by external borrowing $\left|\phi_{t}\right|$ instead of inflationary finance. By construction $\gamma_{t}$ and $\phi_{t}$ are the orthogonal components of these net revenue and external credit shocks.

$$
\epsilon_{\mathrm{t}}=\gamma_{\mathrm{t}}-\phi_{\mathrm{t}}
$$

If, in any period, expansion of domestic credit is too large to be absorbed by the demand for real balances, equilibrium in the money market

$$
M_{t}^{s}=M_{t}^{d}
$$

is restored by adjustment of the exchange rate in a flexible rate system or by offsetting movements of the central bank reserve stock under a controlled rate system. Prolonged difficulties for the central bank arise when this depletion of foreign exchange reserves is the outcome of fundamental disequilibrium (systematic overvaluation) rather than transitory events. The resulting systematic decline of reserves may lead economic agents to doubt the ability of the central bank to sustain the controlled rate. Agents may initiate speculative attacks on the currency which can fulfil their own expectations by collapsing the exchange rate [Obstfeld (1986)].

The shadow exchange rate, $\tilde{S}_{t+1}$, defines the exchange rate that would equilibrate the money market in $t+1$ if a speculative attack were to drive reserves to their minimal level and force the collapse of the controlled exchange rate Under domestic currency convertibility, if agents are cumulatively powerful enough to deplete existing stock of central bank foreign exchange reserves, speculators will attack reseryes

${ }^{5}$ The treatment of this second source of shock alternatively can be interpreted as randomizing the level of net central bank reserve floors. 
at the moment such behavior is expected to yield profits. By equations 1 through 8 , the period $t+1$ shadow exchange rate is derived as:

$\left.\tilde{S}_{t+1}=\left\{1 / a_{t+1}\left\{P^{*}{ }_{t+1}+\alpha_{t+1}\left(a_{t+1}+p_{t+1}\right)\right\}\right\}\left\{\left(a_{1}+a_{3}+a_{t+1}\right) / a_{t+1}\right\}_{\mu t+1}+D_{t}+R_{0}+\left(\gamma_{t+1}-\phi_{t+1}\right)\right\}$

Relative price shocks, $\Omega_{t+1}$, if positive, put downward pressure on the exchange rate by increasing real money demand for transactions purposes. Internal government basic budget shocks, $\gamma_{t+1}$, increase devaluation pressure by increasing the amount of fiscal monetizing. External credit supply shocks, $\phi_{t+1}$, if positive, decrease the pressure on the exchange rate by reducing the need for domestic credit creation.

The conventional approach is to define $\pi_{t}^{s}$, the probability of a (successfui) speculative attack in the beginning of $t+1$ as assessed in period $t$, as analogous to the probability that the expected post-attack exchange rate will exceed the controlled exchange rate: ${ }^{6}$

$$
\pi^{\mathbf{s}}=\operatorname{Pr}_{\mathrm{t}}\left[\tilde{S}_{\mathrm{t}+2}-\mathrm{S}_{\mathrm{t}+1}>0\right]
$$

where $S_{t+1}$ equals $S_{t}$ when the exchange rate is fixed, or equals some other preannounced or bounded level if the exchange rate follows a crawling peg. By rearranging terms to group all random components to the right-hand side of the bracketed expression, and all 'fundamental' variables to the left hand side, the conditional probability of speculative attack or collapse is:

$$
\pi_{t}^{s}=\operatorname{Pr}_{t}\left\{S_{t+1} a_{t+1} \alpha \Omega_{t+1}-\gamma_{t+1}-\phi_{t+1}<K_{t+1}\right\}
$$

where $\left.K_{t+1}=\left(\left(a_{t+1}+a_{1}+a_{3}\right) / a_{t+1}\right)_{t} \mu_{t+1}+D_{t}+R_{c, t+1}-S_{t+1} a_{t+1}\left[P_{t+1}^{*}+\alpha_{t+1} \rho_{t+1}\right]\right\}$

and $\quad a_{t+1}=a_{0}+a_{2} y_{t+1}-a_{1}\left[i^{*}{ }_{t+1}+r_{t+1}\right]$

$\mathrm{K}_{\mathrm{t}+1}$ contains those variables which can be forecast with relatively high accuracy. ${ }^{7}$ To derive a closed form solution for (11), the random terms, $\gamma_{t+1}, \phi_{t+1}$ and $\Omega_{t+1}$, are assumed to be

\footnotetext{
${ }^{6}$ Goldberg (1989) offers a broader interpretation of the probability of collapse in the context of a heterogeneous agent model.

${ }^{7}$ In the empirical application the risk premium is treated as subsumed by the constant.
} 
distributed as displaced exponentials with zero means and variances of $\left(1 / \lambda_{1}\right)^{2},\left(1 / \lambda_{2}\right)^{2}$ and $(1 / w)^{2}$, respectively. The solution to system (11) is:

$$
\pi^{s}=\left[w \lambda_{2} /\left[S_{t+1} a_{t+1} \alpha_{t+1}\left(\lambda_{1}+\lambda_{2}\right)\left(w+\lambda_{1}\right)\right]\right\} \exp \left[\lambda_{1} K^{\prime}{ }_{t+1}\right] \text {, where }
$$

$K^{\prime}{ }_{t+1}=\left\{\left(\left(a_{t+1}+a_{1}+a_{3}\right) / a_{t+1}\right]_{t} \mu_{t+1}+D_{t}+R_{c}-1 / \lambda_{1}+1 / \lambda_{2}-S_{t+1} a_{t+1}\left(P_{t+1}^{*}+\alpha_{t+1} \rho_{t+1}-\alpha_{t+1} / w\right)\right\}^{8}$

This result states that the probability of a speculative attack on foreign currency reserves depends on agents' forecasts of the evolution of a range of economic variables which include domestic credit growth, the systematic overvaluation of domestic goods $\left(\rho_{t+1} \neq 0\right)$, and the possible magitudes of internally and externally generated economic shocks.

\section{The Mexican Experience}

The events surrounding the Mexican crises of the 1980 s are by now familiar. Following a long period of exchange stability and conservative monetary policy, The abundance of petrodollars in the late 1970 s helped the stability of the reigning highly controlled float. This remained in place until early 1981 when a swifter rate of currency depreciation against the dollar [8 to 10 percent per month] was announced along with a promise of no major sharp adjustments. Soon afterwards, currency speculation rose, capital flight increased, and vast amounts of money were shifted into investments and real estate in the United States. In early 1982 new credit flows to Mexico levelled, marking the end of the rapid expansion of private and official commitments Mexico. The Mexican government was able to defend the exchange rate until February 1982 when the government withdrew support of the peso in foreign exchange markets. The exchange rate regime collapsed into a temporary float and the peso depreciated by 67.7 percent. Though July 1982 may be considered the start of Mexico's

\footnotetext{
${ }^{8}$ If shocks were assumed to be normally distributed, rather than exponentially distributed, the probability density function for the combined random variables would not be nearly as tractable. The solution would be $\pi(\mathrm{t})=\int_{-\infty}^{K(t+1)} \int_{-\infty}^{\infty}\left[\sigma_{\mathrm{x}} \sigma_{y}(2 \pi) S(\mathrm{t}+1) a \alpha\right]^{-1} \exp \left[-\mathrm{X}^{2} / 2 \sigma_{\mathrm{x}}^{2}\right] \exp \left[-(\mathrm{X}-\mathrm{Z})^{2} / 2 \sigma_{\mathrm{y}}^{2}\right] \mathrm{dXdZ}$.

The exponential distribution is also intuitively appealing since it highlights the potential for large one-sid3ed expansions of domestic credit while ruling out the unlikely corresponding contractions which appear under the normal distribution.
} 
rationed access to external credit, patterns of total debt service and total new commitments show that new loans directed at sustaining the fixed rate were scarce as early as 1980 . Total debt service exceded total new commitments by steadily rising amounts between 1980 and 1985. Betwen 1982 and 1983 new credit to Mexico fell by approximately 40 percent. ${ }^{9}$

Triggered by the onset of the Mexican debt crisis, in August 1982 the government again succumbed to market speculation and withdrew support for the peso. The collapse led to a temporary closing of all foreign exchange markets and the implementation of a two tier exchange system.

The two tier system was replaced by a crawling peg in September 1983. The crawl provided for daily peso depreciations at a rate of 13 centavos to the dollar. In December 1984 the slippage rate was lincreased to 17 centavos per dollar per day. In March 1985 the slippage rate increased once again, this time to 21 centavos per day. This crawl remained until July 1985 when the government devalued the controlled rate by 16.7 percent, before abandonning the crawling rate altogether in August 1985 in favor of a controlled float. The controlled float was intended to provide for daily adjustments of the exchange rate to compensate for the inflation differential between the United States and Mexico. In practice, the exchange regime was similar to the crawling peg which preceded it.

Based on this credit and currency history, the collapse model for fixed or crawling rate systems is most appropriately applied to the 1980 to 1986 period for Mexico. Although Mexico's externally credit constrained interval begins in 1980 and the tightly controlled exchange regime formally ends in August 1985, results are generated for various subperiods of the full sample. The results for 1980:12 through 1982:9 overlap with the interval studied by Blanco and Garber using quarterly data [1980:IV-1982:III].

\footnotetext{
${ }^{9}$ As measured by asset positions of banks and offshore institutions reporting to the Bank for International Settlements
} 
III. Data Analysis and Estimation: The first step in applying the crisis model to the Mexican experience entails generating one-period ahead forecasts of $t+1$ dated variables $\left[t_{t} \mu_{t+1}, t_{t}{ }^{*}{ }_{t+1}, t_{t} \rho_{t+1},{ }_{t} P^{*} t+1, t_{t+1},{ }_{t} y_{t+1}\right]$. A second order autoregressive and moving average process is applied over rolling 18 month intervals to provide these ex-ante forecasts.

Among the most important elements of the collapse models are the trend behavior of domestic credit and its randomness. After generating ${ }^{\mu_{t+1}}$ forecasts, a residual series $\epsilon_{t}=D_{t}-D_{t-1}-t_{-1} \mu_{t}$ is constructed. This series is used for decomposing domestic credit prediction errors by source, either: i) domestic monetary and fiscal authorities (internally generated shocks); or ii) foreign creditors (externally generated shocks). Using rolling regression over ex-post data for the 18 quarters prior to each period t, the portion of domestic credit shocks attributable to the behavior of external creditors is isolated by regressing $\epsilon_{t}$ against ex-post externally supplied credit, $F_{t}$. This generates an estimate of the component of domestic credit shocks linked in any way to the change in the supply of net external credit to Mexico. It is interpreted as the externally induced shock and is formally written as $\phi_{t}=-\beta \Delta \mathbf{F}_{t}$. The remaining portion of domestic credit shocks is interpreted as that directly induced by domestic authorities: by construction these are the orthogonal residuals, $\gamma_{t}=\epsilon_{t}-\phi_{t}$. Rolling samples of $\phi_{t}$ and $\gamma_{t}$ are analyzed to generate the distributions of expected externally and internally generated shocks to domestic credit. The standard deviation of the data for 18 months, inclusive of $t$, is taken to be the period $t$ forecast of the standard deviation of shocks expected in $t+1,1 / t_{t} \lambda_{2+1}$ and $1 / t_{1, t+1}$. Domestically induced credit variability generally increased gradually throughout the sample with the exception of step increases in early and mid-1982, late 1983 , and mid-1984. Externally induced credit variability increased sharply in mid-1982, at the time of the debt crisis, and began to subside in early 1984 before sharply and continually rising in the latter part of 1984, and again in late 1985. 
This method of decomposition presents an interesting bias to the estimation results. If the correlation between foreign credit contractions and domestic expansions is positive, the random behavior of domestic monetary authorities is biased downward. Since the positive correlation is extremely likely, this implies an implicit upward bias on the role of external credit shocks in Mexico's currency crises. Alternatively stated, this approach may understate the role of domestic monetary authorities since it conservatively estimating their contribution to the forces which trigger speculation and lead to the collapse of an exchange rate systern. If the results still suggest the overwhelming importance of uncertainty attributable to domestic monetary authorities, arguments which shift the emphasis to the actions of external creditors would not be highly credible.

The scale of domestic credit uncertainty surrounding domestic credit policies of monetary authorities grew fairly steadily between 1980 and 1987. Marked increases in uncertainty levels are evident in early 1982 , prior to the poignant currency and debt crises of the $1982 / 1983$ period, and in early 1985 prior to the abandonment of the crawling peg regime. Uncertainty surrounding external credit flows was fairly stable at low levels through June of 1982. At the time of the debt crisis and the temporary closing of Mexico's foreign exchange market in August 1982, uncertainty surrounding foreign credit flows substantially rose and remained at new high levels through early 1984. A substantial rise in the uncertainty surrounding external credit flows to Mexico occured throughout the remainder of 1984 and peaked ${ }^{10}$ in February 1986. A highly controlled float was in effect at that point.

\footnotetext{
${ }^{10}$ The peak described is local since the uncertainty surrounding external credit flows declined sharply in 1986 and early 1987 before reaching new highs in mid 1987 and 1988.
} 
To capture the role of departures from purchasing power parity (PPP) during crisis periods, ${ }^{11}$ patterns of deviations from $P P P, P_{t}--S_{t} P^{*}$, are decomposed into the sum of systematic (predictable using period $t-1$ information) and random components, $t-\rho_{t}$ and $\Omega_{t}$.

$$
P_{t} / S_{t}-P_{t}^{*}={ }_{t-1} \rho_{t}+\Omega_{t}
$$

The predictable component is used to generate forecasts of expected future deviations from PPP, ${ }_{t} \rho_{t+1}$, and the residual relative price shocks. As in the case of monetary shocks, the expected future distribution of relative price shocks can be parameterized to yield a forecast of the expected standard deviation of relative price shocks, $1 / t w_{t+1}{ }^{12}$ Evolution of the random component of purchasing power parity deviations is illustrated by the plot of $1 / t_{t} w_{t+1}$ in Figure 3. Prior to the February 1982 steep devaluation of the peso, the markets perceived relatively low levels of risk associated with relative price movements. Due to the sharp realignments in 1982 , the risk associated with relative prices soared, peaking in mid 1982 but remaining at exceptionally high levels through 1984. A period of relative price stability occured during the crawling rate interval between mid-1984 and mid-1985. With the abandonment of the crawl in favor of a controlled float in late 1985, relative price uncertainty increased substantially but by no means approached the levels of the 1982 through early 1984 interval.

$R_{c, t+1}$ also must be specified before the system is estimated. While the lowest levels of reserves that the central bank will tolerate at any time $t$ may be known by central bankers, these values are unavailable publicly until the regime collapses. ${ }^{13}$ Blanco and Garber

\footnotetext{
${ }^{11}$ Previous empirical studies of crises did not fully capture these forces leading to estimation biases. While Blanco and Garber allowed for random deviations from purchasing power parity, Cumby and van Wijnbergen considered neither systematic or random departures from purchasing power parity.

${ }^{12}$ Using the criterion of out-of-sample predictive performance, an ARMA procedure predicted relative price gaps with systematically smaller forecast errors than richer alternative approaches applied.

${ }^{13}$ Efforts by Goldberg (1988) to pin down patterns in $R_{c}$ using cross country analyses revealed only that the level is inversely related to access to international liquidity.
} 
modelled the reserve floor as a constant multiplied by an index of U.S. import prices. Cumby and van Wijnbergen assumed the reserve floor was described by a uniform distribution with an upper bound as the current level of reserves and the lower bound as minus the central bank's gross foreign liabilities. While both are reasonable approaches to this illusive statistic, a conservative test of the out-of-sample predictive performance of this model frames the choice of an ad hoe specification over the use of ex-post information. To highlight the importance of the reserve floor specification for the results, all estimation results are conducted separately for a range of reserve floors between $R_{c}=-\$ 200$ million and $\$ 1$ billion 1977 US dollars. The negative reserve floors are included to capture the perception that the central bank may have had access to emergency lines of credit for the purpose to defending the currency. Real reserve floors are translated from dollars into nominal domestic currency (billions of pesos) using the official exchange rate and the Mexican consumer price index.

\section{Iterative Estimation of Money Market Equilibrium}

The next step in estimating the collapse model is to estimate money demand parameters. Since one of the right hand side variables, the expected change in the exchange rate, is a nonlinear function of money demand parameters a multi-stage iterative estimation procedure is applied to equations II to I5 drawn from the model of Section II.

$$
\begin{aligned}
& M_{t} / Q_{t}=a_{0}-a_{1} i_{t}+a_{2} y_{t}-a_{3}\left\{\left[1-\pi_{t}\right]\left[S_{t+1}^{a}-S_{t}\right] / S_{t}+\left[\pi_{t}\right]\left\{\left[\tilde{S}_{t+1}-S_{t}\right] / S_{t}\right\}\right. \\
& a_{t+1}=a_{0}+a_{2} y_{t+1}-a_{1} t^{i^{*}}{ }^{*}+1 \\
& \left.\tilde{s}_{t+1}=\left\{1 / t^{a_{t+1}}\left\{t P^{\star}{ }_{t+1}+{ }_{t} \alpha_{t+1}\left(t \rho_{t+1}\right)\right\}\right\}\left\{\left(a_{1}+a_{3}+a_{t+1}\right) / a_{t+1}\right\}_{t} \mu_{t+1}+D_{t}+{ }_{t} R_{c, t+1}\right\} \\
& { }_{t} K_{t+1}=\left[\left(a_{t+1}+a_{1}+a_{3}\right) / a_{t+1}\right]_{t} \mu_{t+1}+D_{t}+{ }_{t} R_{c, t+1}-1 / \lambda_{t} \lambda_{1, t+1}+1 / \lambda_{2, t+1} \\
& -S_{t}{ }_{t} a_{t+1}\left({ }_{t} P^{*}{ }_{t+1}+{ }_{t} \alpha_{t+1}{ }_{t} \rho_{t+1}-{ }_{t} \alpha_{t+1} /{ }_{t} w_{t+1}\right) \\
& \left.\left.\pi_{t}^{s}=l_{t} w_{t+1} t^{\lambda}{ }_{2, t+1} /\left[S_{t} t_{t+1} t_{t+1} \alpha_{t}\left(\lambda_{1, t+1}+t_{t} \lambda_{2, t+1}\right)\left(w_{t+1}+t_{t} \lambda_{1, t+1}\right)\right]\right)\right] \exp \left(\lambda_{t} \lambda_{1, t+1} K_{t+1}\right]
\end{aligned}
$$


Step 1: Start-up values of $a_{0}, a_{1}$, and $a_{2}$ are generated by estimating the money market equilibrium condition, omitting the currency substitution term. This system is roughly comparable in structure to those of previous studies, except that those studies omitted the currency substitution term.

Step 2: The first-pass values of the parameters and the start-up value for parameter $a_{3}$ are input into equations 12 through 15 to generate first pass-estimates of the post-collapse shadow rate and the collapse probability. ${ }^{14}$ In this step the information on the composition and distribution of shocks and data forecasts are utilized.

Step 3: The money market equilibrium condition is reestimated using shadow rate and probability estimates from the previous pass. New parameter estimates are generated.

Step 4: New parameter estimates are used in equations 12 through 15 to generate new estimates of the post-collapse shadow rate and the collapse probability.

Steps 4 and 5 are repeated until convergence, where convergence is defined as the attainment of local maximum within a finite number of passes through the data ${ }^{15}$

\section{Estimation Results}

The model is estimated using a range of assumptions over parameter stability within intervals and a range of reserve floors. While the full sample of data spans 1980:12 to

\footnotetext{
${ }^{14} \mathrm{~S}(\mathrm{t}+1)$ is the announced one-period ahead exchange rate. The final results are locally independent of the choice of start up value for $a_{3}$.

${ }^{15}$ In practice, the system generally is estimated for up to 15 passes through the data. Although the parameter estimates converged to stable values in most runs, it is unknown whether the final values represented local or global maxima. Other estimation issues arise because the generated first pass estimates of $a_{0} a_{1}$ and $a_{2}$ are subject to omitted variables bias to the extent that the expected change in the exchange rate is correlated with the interest rate and income. This bias reduces to a function of the covariance of nominal domestic credit wh nominal interest rates and real income respectively. While the convergence results suggest that this omitted variables bias disappears, it is unclear if there is any residual effect on final parameter estimates.
} 
$1986: 12{ }^{15}$ estimation over subintervals provides evidence that money demand was unstable over this period. Below, results are presented for the pre-1983:10 and post 1983:9 periods. The break point is the time of implementation of the crawling peg regime. In the early interval, money demand shows a positive and significant income elasticity of demand, as expected. The interest sensitivity and curency substitution motives for money demand holdings are both positive and significart in this early period, with the sign reversal contrary to expectations. In the post 1983.9 interval, the elasticity of money demand to the interest rate was the only significant term in the money demand equation.

For the early interval, the bigher the reserve floor the higher the prediction of a currency collapse. The one-period-ahead collapse probability predictions are shown in Figure 5 for the range of reserve floors $[\$-100$ million, $\$ 0.00$, $\$ 100$ million, $\$ 200$ million, $\$ 300$ million, and $\$ 500$ million in 1977 prices].

While runs over the different collapse probabilities all behave qualitatively similar, the higher reserve floor estimates, as expected, are associated with higher predictions of collapse probabilities and slightly different shadow exchange rate forecasts since different money demand parameter estimates are used in generating the forecasts. Figures 5 and 6 present the estimates of one period ahead probabilities of collapse for a range of reserve hoors and actual excharige rates alongside predicted shadow exchange rates for the case $R_{c}=\$ 200$ million (in 1977 prices).

Collapse probabilities were uniformly high in November 1981, but the central bank did not experience a level of run which would cause a currency collapse. Since the model is of the behavior of a representative agent, this result would imply that the agents were confident that the central bank had access to external credit which would enable it to

\footnotetext{
${ }^{16}$ While the sample estimated begins in $1980: 12$, the full sample of the data begins in 1977. This data is not used in estimation since at least 36 months of observations are lost due to the procedures used for forecasting the various series.
} 
withstand speculation. While skepticism remained high for many types of agents, using reserve floors to approximate type, the shadow exchange rate results suggest that the scale of devaluation was underpredicted by even the high reserve floor model. This steep devaluation convinced the low reserve floor agents of the short term sustainability of the peso, but the high floor agents were less sanguine. By April 1982, expansionary monetary policies undermined the restored confidence in the peso leading low reserve floor agents to predict an additional 4 percent devaluation and the high reserve floor agents to predict an additional 16 percent devaluation. Central bank foreign exchange reserves began to fall dramatically, although they were not instantaneously depleted. The shadow rate results suggest that the predicted devaluation rose steadily though the course of the speculative attack on central bank ieserves in the months which followed. The devaluation predictions rose to the range of 23 to 32 percent by Algust 1982 at which time all agents ${ }^{17}$ predicted the demise of the peso, and again to the range of 36 and 45 percent by November. The devaluation in December was 93 percent of the previous month's peso value.

This major realignment temporarly satisfied the more optimistic, low reserve floor agents, but did not satiate the more critical, high reserve noor agents who predicted that an additional 10 percent devaluation would be needed in January 1983. This implies that, depending on the composition of agents in the economy, the dual exchange rate initiated at the start of 1983 may have been set at overvalued levels. For all reserve floor simulations, the prevailing exchange rates soon were undermined by the quickened pace of domestic credit expansion and inflation.

Interval estimates strongly suggest a structural shift in money market activity at around this period. This is not surprising, given the realization of the magnitude of the debt crisis, the implications for future credit flows and the restructuring of the foreign

\footnotetext{
${ }^{17}$ All agents are those defined by the range of possible view of critical reserve floors.
} 
exchange rate regime. While numerous estimates were conducted over a range of subsampels of the full data set, the money demand estimates over the full sample 1980:12-1986:12 are meaningless because of the structural instability and generally are uninformative for the latter half of the sample. Therefore, below the probability of collapse figures represent probabilities generated for the 1983:10 to 1986:12 under the assumption that the parameters estimated for the early interval were still valid for the latter interval.

The results suggest that the rate of crawl for the peso was inadequate at least through August 1984. The significant increase in uncertainty surrounding money creation appears to have dominated the $\pi_{t}$ jump observed in December 1983. The subsequent contraction of domestic credit in January 1984 lowered collapse expectations but generally failed to restore faith in the sustainability of the existing crawl.

The sharp rise in domestic credit creation forecasts and the high levels of surrounding uncertainty contributed to the April 1984 predictions of a more steeply devalued peso. As foreign exchange reserves fell sharply in that period, some measure of confidence in the peso crawl was restored by the monetary authorities pulling in on the reigns of domestic credit. A full scale speculative attack appears to have been averted. For the remainder of 1984, the peso followed a rate of crawl which, according to the collapse estimates, was sufficient to minimize currency speculation. The increase in the rate of crawl in December 1984 was associated with an interval of peso strength in the sense of accumulating foreign exchange reserves. The increase in uncertainty surrounding external credit flows appreared to have little effect on shifting $\pi_{t}$ to critically high levels. Moreover, the model predicts that collapse probabilities remained close to zero for the remainder of the sample. This could suggest that confidence in the peso was restored by the successful application of the crawl and the controlled float that followed. However, these results could also reflect a problem with the application of the collapse model to this latter interval. 
Blanco and Garber (1986) had modelled speculation against the peso using quarterly data for the 1973:IV to 1982:IIl interval, a single reserve floor and using a more simplified framework. While that paper greatly enriched our understanding of the potential of such models, the broader framework developted and estimated herein provides more plausible shadow exchange rate and collapse probability values and much greater insight into the forces driving crises in the overlapping interval.

VI. Decomposition of "Causes" of the Currency Crises: Simulation Results

In this section, the set of parameter values associated with each reserve floor are used in generating probability and shadow exchange rate values for a range of scenarios. Specifically, the pre $1983: 10$ interval estimations using $R_{c}$ values ranging from $-\$ 100$ million to $\$ 500$ million (in 1977 dollars) generated the sets of parameter estimates presented in Table 1.

Table 1: Parameter Values from Runs using Pre 1983:10 data, by Reserve Floor

\begin{tabular}{|c|c|c|c|c|c|c|}
\hline $\mathrm{Rc}$ & $-\$ 100$ & 0.00 & $\$ 100$ & $\$ 200$ & $\$ 300$ & $\$ 500$ \\
\hline$a_{0}^{*}$ & 0.000 & 0.000 & 0.000 & 0.000 & 0.000 & 0.000 \\
\hline a. & -0.293 & -0.285 & -0.283 & -0.288 & -0.273 & -0.273 \\
\hline$a_{2}$ & 0.013 & 0.013 & 0.013 & 0.013 & 0.013 & 0.014 \\
\hline$a_{3}$ & -1.670 & -1.847 & -1.875 & -2.035 & -2.100 & -2.112 \\
\hline
\end{tabular}

* The constant term was insignificantly different from zero in all runs and is set equal to zero in simulations. All other parameters are highly significant.

These sets of parameters are used in simulations which generate the shadow exchange rates and collapse probability estimates under the assumption that these parameters values persisted and for each of the exercizes shown in Table 2. The results generated are for the full sample $1980: 12$ to $1986: 12$. 
Table 2: Simulations Conducted Using Early Interval Parameters, by Reserve Floor

\begin{tabular}{cccc}
$1 / \lambda_{1}$ & $1 / \lambda_{2}$ & $1 / w$ & ${ }^{\mu_{t+1}}$ \\
\hline $0.001 \cdot 1 / \lambda_{1}$ & $0.001 \cdot 1 / \lambda_{2}$ & $0.001 \cdot 1 / \mathrm{w}$ & $0.001 \cdot 1 /{ }_{t} \mu_{t+1}$ \\
$0.50 \cdot 1 / \lambda_{1}$ & $0.50 \cdot 1 / \lambda_{2}$ & $0.50 \cdot 1 / w$ & $0.50 \cdot 1 / t_{t+1}$ \\
$1.00 \cdot 1 / \lambda_{1}$ & $1.00 \cdot 1 / \lambda_{2}$ & $1.00 \cdot 1 / w$ & $1.00 \cdot 1 / t_{t+1}$ \\
$2.00 \cdot 1 / \lambda_{1}$ & $2.00 \cdot 1 / \lambda_{2}$ & $2.00 \cdot 1 / w$ & $2.00 \cdot 1 / t_{t} \mu_{t+1}$ \\
\hline
\end{tabular}

Figures 7 through 10 show probability rate estimates for a representative subset of these runs. The results shown are for the case of $R_{c}=\$ 100$ million (1977 dollars).

The first striking results is that increasing the variability of internally generated shocks generally decreases rather than increases the probability of a speculative attack on the peso. (See Figure 7.) Although counter-intuitive, Goldberg (1989) noted that this theoretical possibility arise when $1 / \lambda_{1 t}$ is sufficiently large so that further increases in the stochastic behavior of domestic credit decrease the expectation that the shadow rate will exceed the controlled rate in the following period. Consider the role of these shocks in the 1981:6 through 1983:9 interval. If the yariability of internally generated shocks were halved, currency speculation (if positively related to $\pi_{t}$ ) is predicted to have been even higher in the periods preceding the February 1982 realignment and in early 1983. The model suggests that doubling the uncertainty surrounding internal credit growth could have reduced the probability of the collapse by as much as 50 percent prior to February 1982 and could have significantly reduced speculation in the months which followed.

Decreasing the variability of external credit shocks, on the other hand, would have reduced the probability of collapse, but not by very large amounts. A reduction of $1 / \lambda_{2 t}$ to one thousandth of its level generally reduced $\pi_{t}$ by less than 5 percent in each period. This is a strong result. It suggests that external credit shocks contributed very little to the currency crises of Mexico in the 1980s. This result is strengthened further if one 
considers that the construction of $1 / \lambda_{2}$ tended to overstate rather than understate its importance.

The role of relative price shocks in the onset of crises varies over time. Decreasing the variability of relative prices uniformly reduced the probability of collapse. The significance of this effect dramatically changed prior to and following the February 1982 realignment, when $1 / w_{\text {c }}$ rose sharply. Pre-February 1982 , reducing relative price uncertainty would have had little effect on currency speculation. Following this period, however, $1 / \mathrm{w}_{\mathrm{t}}$ contributed greatly to speculation since, according to the model, agents were reluctant to take another sharp reduction in the purchasing power of their holdings. This force becomes even stronger as the share of traded goods in the home consumption bundle rises. While the model predicts that reducing $1 / w_{t}$ sharply in the periods following the realignment would have dramatically cut the speculation through July 1982 , following Mexico's August 1982 announcements none of the agents modelled would have continued to hold pesos ever if the expected variability of relative prices was reduced to near zero.

It should be noted, however, that the important contribution of expected relative price shocks again surfaces in the months beginning with December 1982 when the government attempted to bring the peso under control. Consider the $\pi_{t}$ estimates shown in Table 3 and depicted in Figure 9.

These simulation results are difficult to interpret since $1 / w_{t}$ is a function of past surprise devaluations. However, $1 / w_{t}$ would increase by a much smaller amount if there were small rather than large realignments to the peso. The results suggest that the speculative attacks against the peso might have been reduced, and confidence in the peso restored in early 1983; if the government had implemented a series of small realignments rather than the 67 percent and 93 percent devaluations which occured in February and November of 1982 . Of course, the probability of collapse nonetheless rises again in the 
second half of 1983 serving as a reminder that neither a fixed rate or crawling peg system are sustainable in the presence of other, inconsistent policy actions.

Table 3: Collapse Probabilities for Scaled 1/w Simulations, 1982:8 to 1983:12

(for $R_{e}=\$ 100$ million 1977 dollars)

Date Collapse Probabilities

$\left(.001 \cdot 1 / w_{t}\right) \quad\left(0.50 \cdot 1 / w_{t}\right) \quad\left(1.00 \cdot 1 / w_{t}\right)$

$\begin{array}{llll}1982: 10 & 1.000 & 1.000 & 1.000 \\ 1982: 11 & 1.000 & 1.000 & 1.000 \\ 1982: 12 & 0.012 & 0.127 & 1.000 \\ 1983: 1 & 0.004 & 0.819 & 1.000 \\ 1983: 2 & 0.008 & 0.078 & 1.000 \\ 1983: 3 & 0.010 & 0.108 & 1.000 \\ 1983: 4 & 0.007 & 0.079 & 1.000 \\ 1983: 5 & 0.007 & 0.076 & 1.000 \\ 1983: 6 & 0.005 & 0.059 & 1.000 \\ 1983: 7 & 0.032 & 0.365 & 1.000 \\ 1983: 8 & 0.032 & 0.484 & 1.000 \\ 1983: 9 & 1.000 & 1.000 & 1.000 \\ 1983: 10 & 1.000 & 1.000 & 1.000 \\ 1983: 11 & 1.000 & 1.000 & 1.000 \\ 1983: 12 & 1.000 & 1.000 & 1.000\end{array}$

Finally, the next set of simulations, shown in Figure 10, derives the collapse probabilities under the assumption that the forecast growth of domestic credit was either halved or doubled. Collapse probabilities were at low levels until November 1981, when domestic credit jumped dramatically. By the construction of the signal extraction problem, this increased both $t_{t+1}$ and $1 / \lambda_{1 t}$. If ${ }_{t} \mu_{t+1}$ were halved in 1982 and 1983 (with $1 / \lambda_{1 t}$ unchanged), the currency speculation may have been reduced, but the dynamics of $\pi_{t}$ would have been quite similar. Yet, if both ${ }_{t} \mu_{t+1}$ and $1 / \lambda_{1 t}$ were halved, the outcome would be quite different since $\pi_{t}$ is decreasing in $1 / \lambda_{1:}$. Reducing both ${ }_{t} \mu_{t+1}$ and $1 / \lambda_{1 t}$ by 50 percent leads to higher collapse probabilities that are larger than if actual yalues were unchanged. 


\section{V1. Concluding Remarks}

This application of a speculative attack model to Mexico's experiences in the 1980 s suggests that domestic monetary and fiscal policy rather than external credit shocks were the driving forces in triggering speculative attacks on the Mexican peso in the 1980s. The model successfully predicted the realignments of the peso which occured in this period, and generated probabilities of speculatiye attacks that were conditioned on the assumed lower limit on central bank foreign exchange reserve holdings. The simulation results suggest that reducing domestic credit growth, increasing the uncertainty surrounding this growth, and reducing the size and perhaps increasing the frequency of currency realignments may have greatly reduced the amount of currency speculation against the peso in some of the crisis periods between 1980 and 1986.

The results also suggest that more attention be focussed on the importance of heterogeneous agents for the timing and magnitude of speculative attacks on a currency. Specifically, it is shown that by varying the assumed critical reserve floor, the predicted shadow rate and collapse probabilities also greatly change While the crisis literature generally models balance of payments crises using a representative agent framework, these results suggest that if different agerts are endowed with different perceptions about central bank access to liquidity, they may be triggered to speculate against the peso at distinct points in time. 
Internal Monetary Shocks

(Standard Deviation)

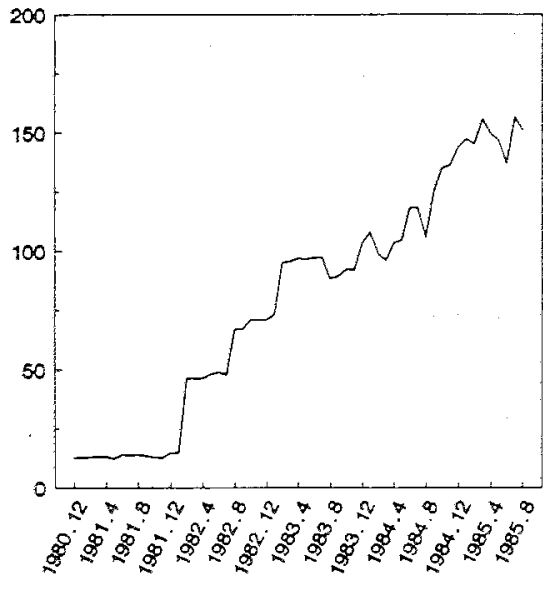

$\operatorname{Tim} \theta$

Figure 1

\section{External Monetary Shocks}

(Standard Deviation)

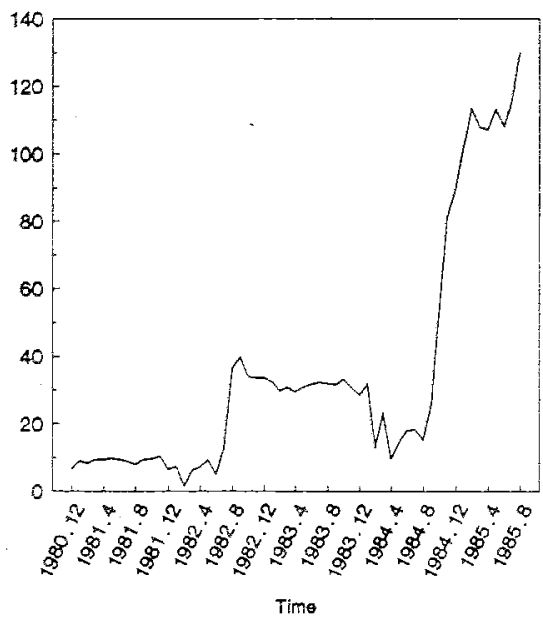

Figure 3
Forecast Domestic Credit Growth

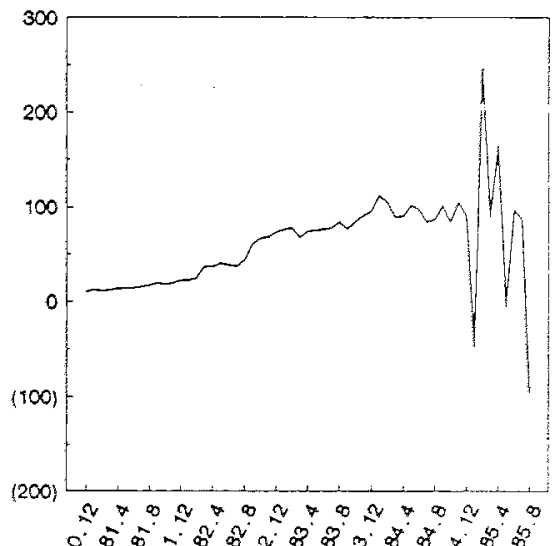
8.

Figure 2

\section{Relative Price Shocks}

(Stenderd Deviation)

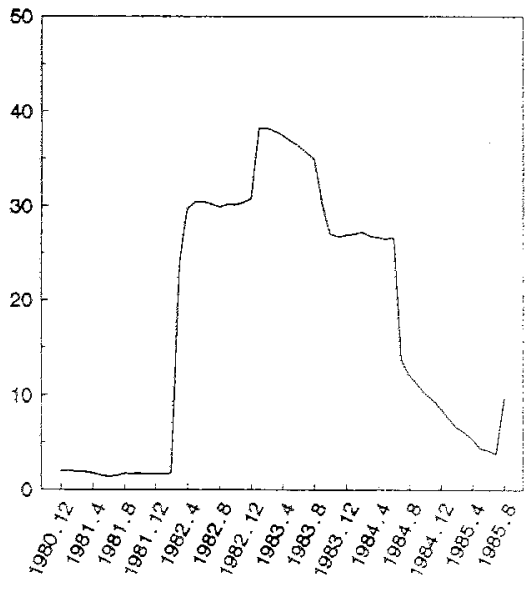

$\operatorname{Time}$

Flgure 4 


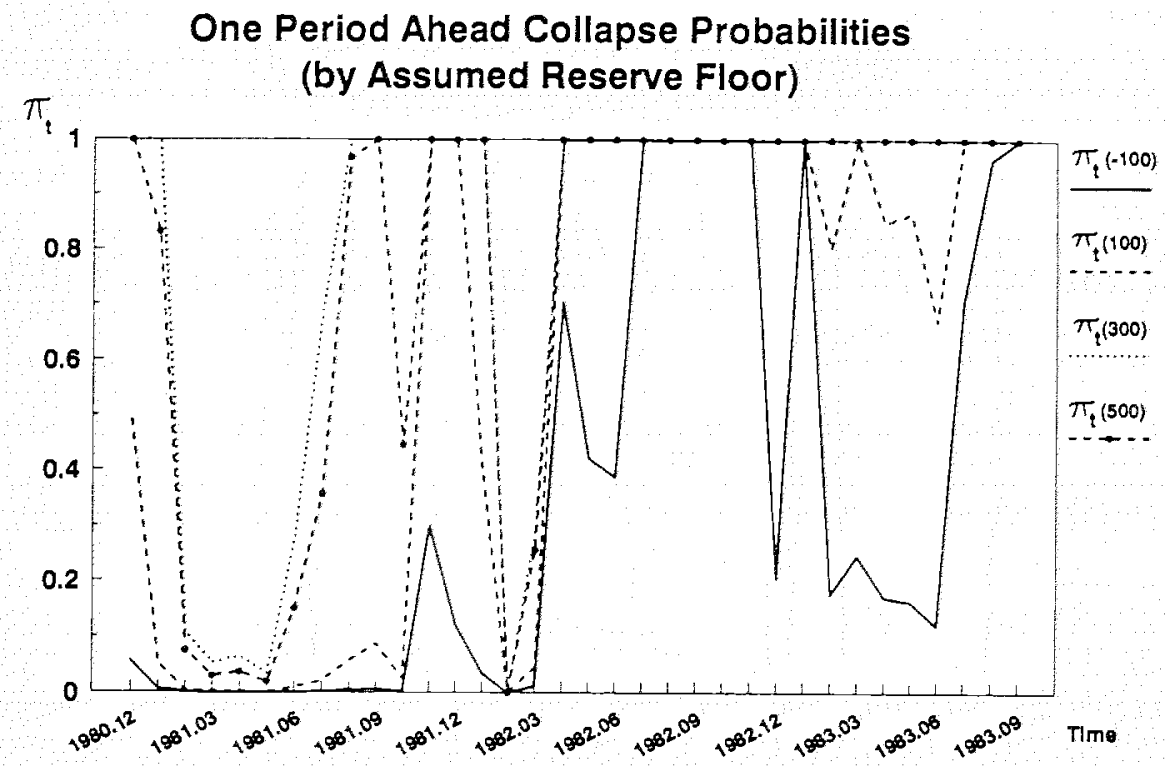

Figure 5

Actual Exchange Rate and Forecast Shadow Rates

$\tilde{\mathbf{s}}, \tilde{\mathrm{s}}$

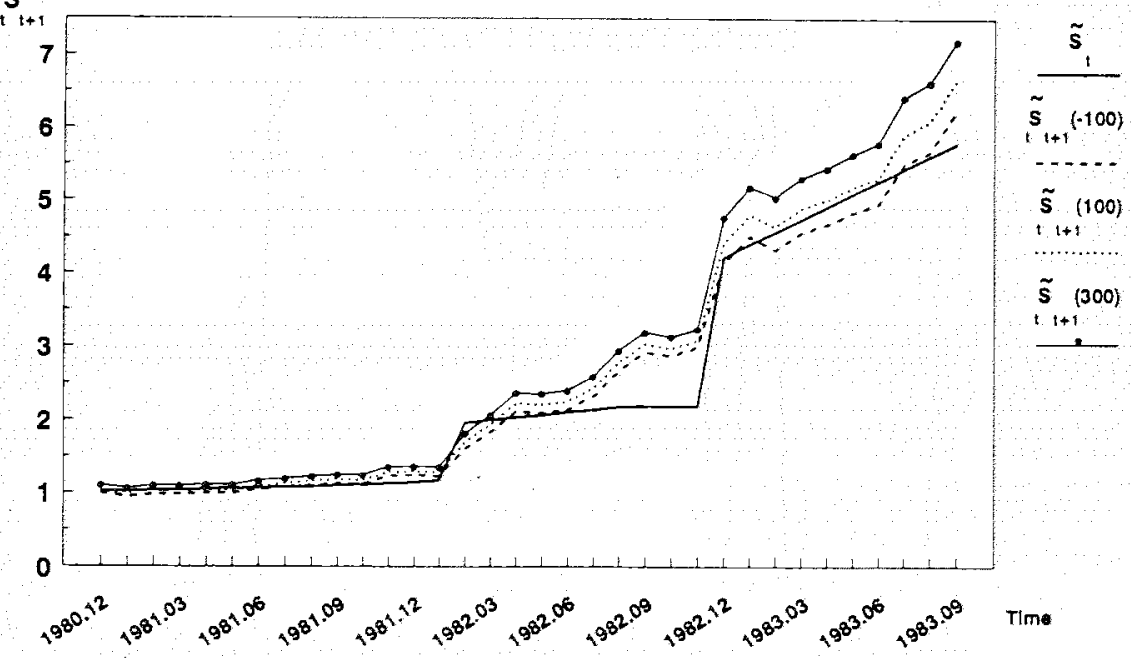

Figure 6 


\section{Simulated Collapse Probabilities}

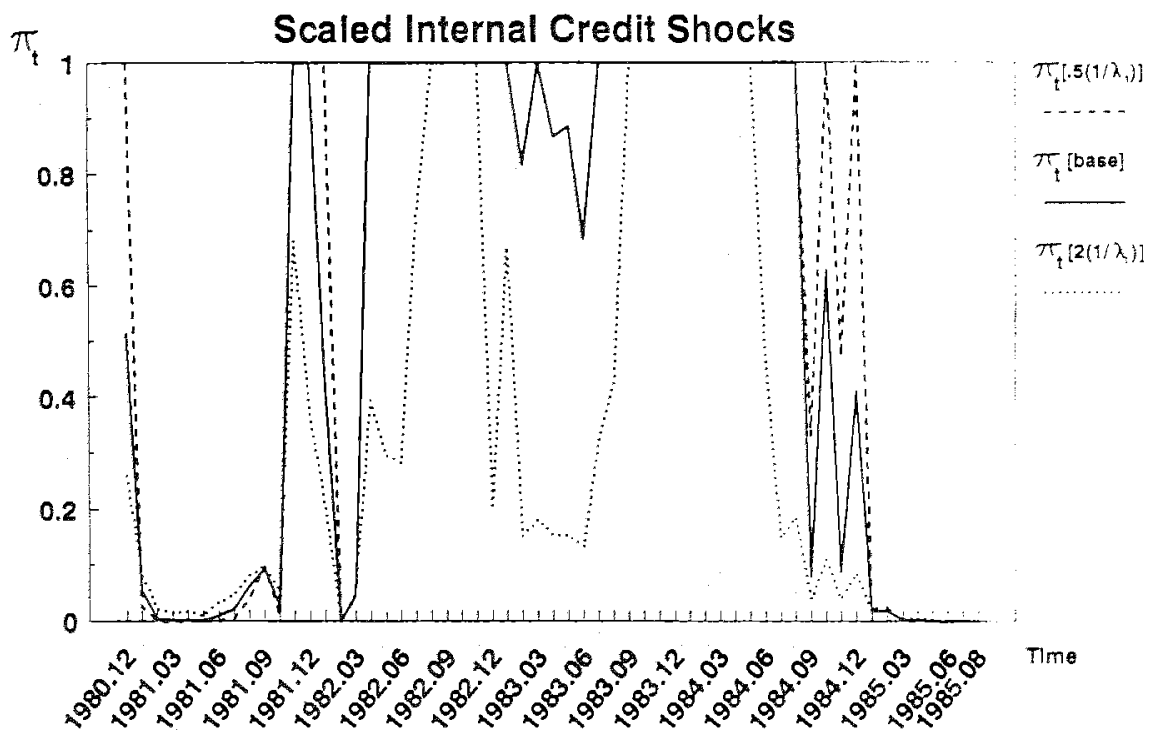

Figure 7

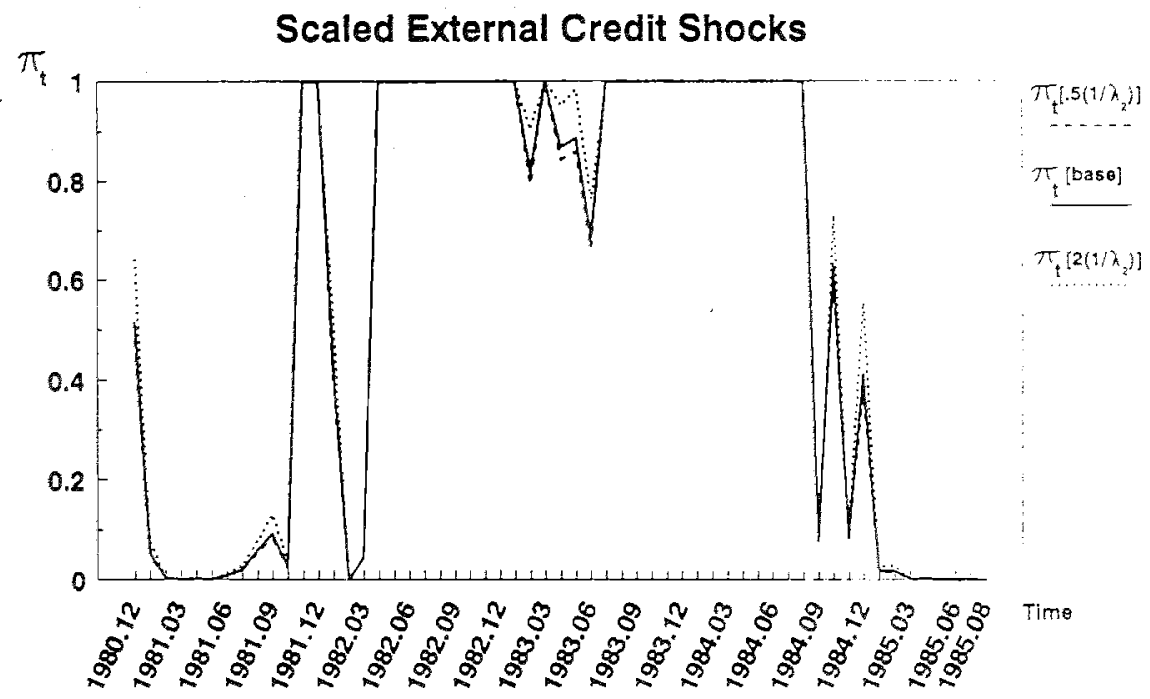

Figure 8

Note: Probabilities calculated using $R_{C}=\$ 100$ million. 


\section{Simulated Collapse Probabilities}

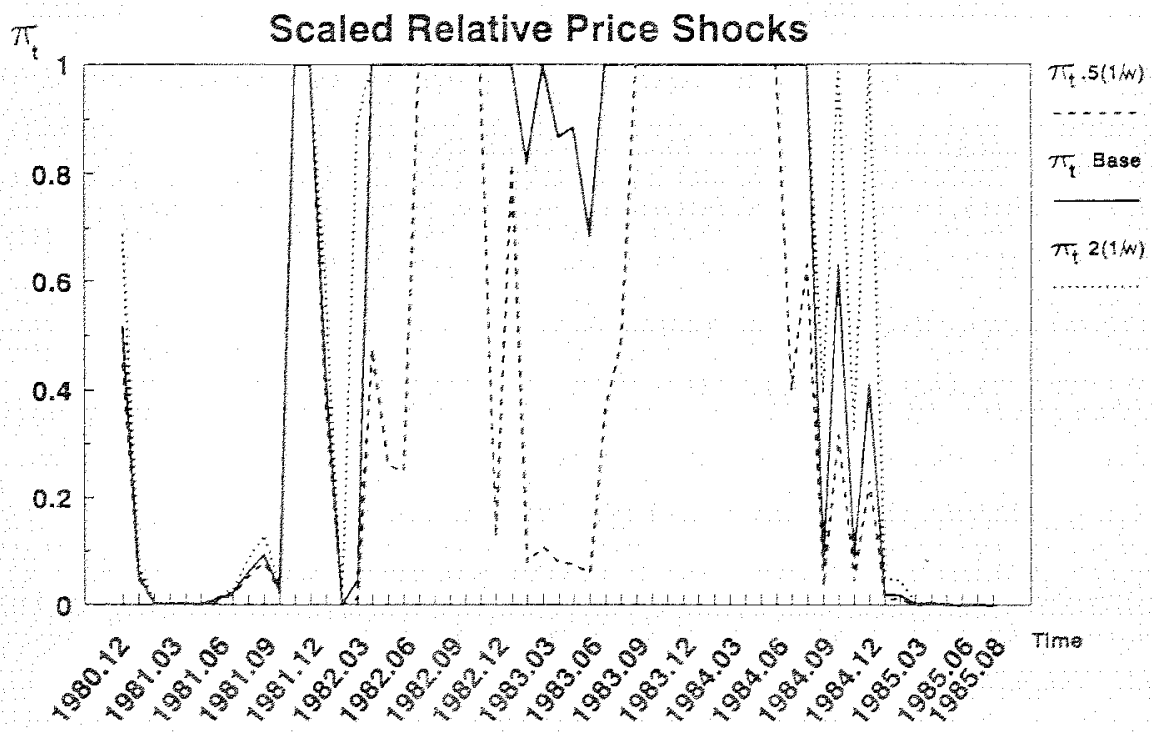

Figure 9

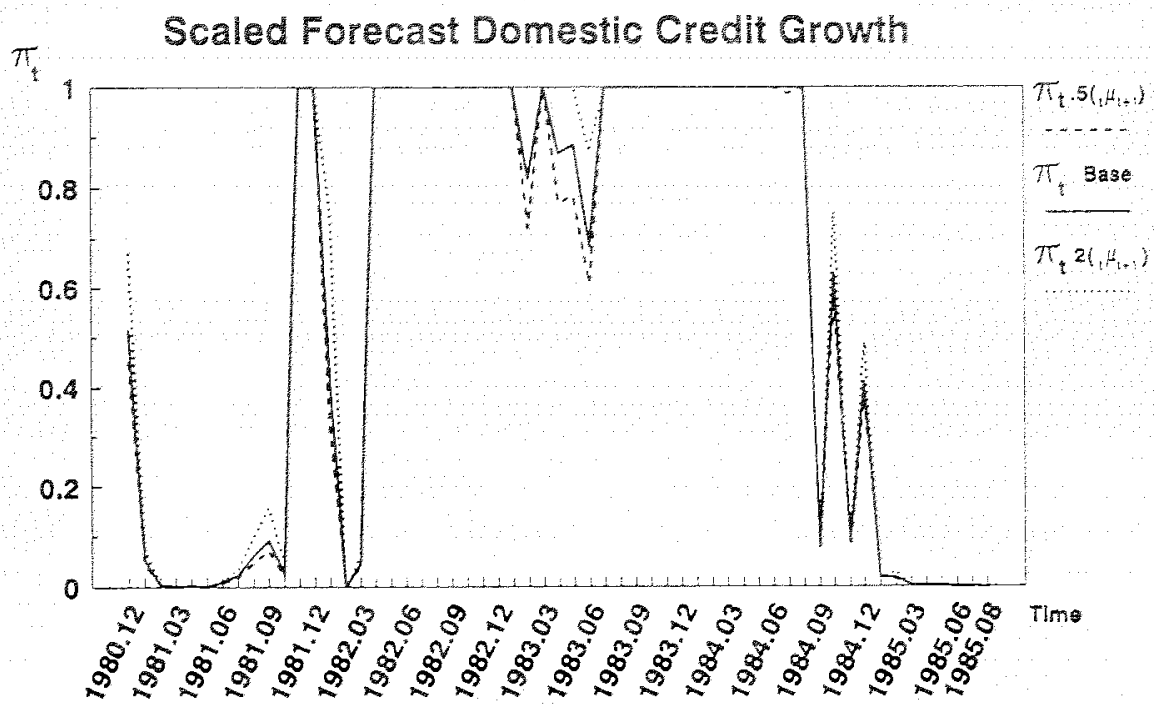

Figure 10

Note: Probabilities calculated using $R_{c}=\$ 100$ million. 


\section{Data Appendix}

$\mathrm{D}_{\mathrm{t}}$ : claims on Mexican government by Bank of Mexico, billions of pesos. IFS line $12 \mathrm{a}$.

$S_{t} R_{t}: \quad$ foreign assets of Bank of Mexico, IFS line 11 .

$F_{\mathrm{t}}$ : Bank for International Settlements, net asset position vis-a-vis Mexico

$i_{t}$ : Mexico' bank deposit rate, in percent per annum, IFS.

$\mathrm{i}_{\mathrm{t}}$ : United States monthly $\mathrm{T}$-Bill rate.

$P_{t}: \quad$ Consumer price index, Mexico, IFS.

$\mathrm{P}_{t^{*}} \quad$ United States wholesale price index, IFS.

$\alpha_{\mathrm{t}}$ : Exports plus Imports divided by GDP, IFS.

$y_{t}$ : Mexico's GDP, interpolated to monthly data using production patterns.

$\mathrm{S}_{\mathrm{t}}$ : Domestic currency price of U.S. dollars, IFS. 


\section{BIBLIOGRAPHY}

Blanco, H. and P.Garber, "Recurrent Devaluation and Speculative Attacks on the Mexican Peso", Journal of Political Economy, (Eebruary 1986).

Buiter, W., "Borrowing to Defend the Exchange Rate and the Timing and Magnitude of Speculative Attacks" Journal of International Economics, vol.23, no.3/4 (1987).

Cumby, R. and S, van Wijnbergen, "Fiscal Policy and Speculative Runs on the Central Bank Under a Crawling Exchange Rate Regime: Argentina 1979-1981", Journal of International Fronomics, September 1988.

Flood, R. and P. Garber, "Collapsing Exchange Rate Regimes: Some Linear Examples", Journal of International Economics, vol 16 (1984).

Flood, R. and R. Hodrick, "Real Aspects of Exchange Rate Choice with Collapsing Fixed Rates", Journal of International Economics, vol.2\%, no.3/4 (1986).

Goldberg, L., "Colupsing Exchange Rate Regimes" Shocks and Biases", National Bureau of Economic Research working paper 2702 (1988).

C.V. Starr Discussion Paper $89-01$, New York University.

Collapsing Exchange Rate Regimes: A Theoretical and Empirical Investigation, Ph.D.Thesis, Princetor University, (January 1988).

Grilly V., "Buying and Selling Attacks on Fxed Exchange Rate Systems", Journal of international Economics, vol.20 (1986).

Krugman, $P_{4}$ "A Model of Balance of Payments Crises", Joumal of Money, Credit and Banking, vol.11, no.3 (August 1979), 311-325.

Obstfeld, M., "Balance of Payments Crises and Devaluation", Journal of Money. Credit and Banking, vol.16; no.2 (May 1984).

Economic Review vol.76 (March 1986).

van Wijnbergen, S., "Fiscal Deficits, Exchange Rate Crises and Inflation", The Foerder Institute for Economic Research, Tel Aviv Unversity, Working Paper no. 2-86 (1986). 